\title{
Announcements
}

\section{Resident Traveling Fellowship in Pediatric Neurosurgery}

\section{2nd International Symposium on New Horizons in Pediatric İMeurosurgery/lMeurology}

The Pediatric Section of the American Association of Neurological Surgeons has established a traveling fellowship for residents in neurosurgical training. The fellowship is intended to cover the travel and living expenses for up to 1 month for residents who wish to pursue additional experience in Pediatric Neurosurgery during their residency years. The 1-month fellowship can be spent in any activity which broadens the resident's exposure to Pediatric Neurosurgery, and might include observation at a clinical or research center, or any other relevant activity. The maximum fellowship stipend is USD2,500. Interested residents should prepare a brief statement regarding the purpose of the proposed fellowship and their expenses, obtain written permission of their program director and that of the institution where they will seek the fellowship, and direct their application to:

\section{R. Michael Scott, MD}

Department of Neurosurgery

The Children's Hospital

300 Longwood Avenue

Bader319

Boston, MA 02115 (USA)

Tel. 02115 (617) 735-6011
Jerusalem, Israel, February 9-13, 1998

For further details kindly contact:

Prof. Shaul Harel or Dr. Shlomo Constantini

cerer 61290 (I Box 2904

Tel Aviv 612

Tel.(3) 517 5150, Fax (3) 517]5155

E-Mail trgt@netvision.net.i

Modified Lateral Decubitus Position PediatrNeurosurg 1996;25:210-213 